\title{
Efficacy and safety of single-inhaler triple therapy of glycopyrronium, formoterol and fluticasone in patients with COPD: a double-blind, randomised controlled trial
}

\author{
Sundeep Salvi ${ }^{1}$, Akash Balki ${ }^{2}$, Srikanth Krishnamurthy ${ }^{3}$, Sagar Panchal ${ }^{4}$, Saiprasad Patil ${ }^{4}$, Rahul Kodgule ${ }^{5}$, \\ Hitesh Khandagale ${ }^{6}$, Amol Pendse ${ }^{6}$, Wen $\mathrm{Wu}^{7}$, Shabbir Rangwala ${ }^{6}$, Monika Tandon ${ }^{5}$ and Hanmant Barkate ${ }^{4}$
}

${ }^{1}$ Chest Research Foundation, Pune, India. ${ }^{2}$ Shree Hospital and Critical Care Center, Nagpur, India. ${ }^{3}$ Sri Bala Medical Centre and Hospital, Coimbatore, India. ${ }^{4}$ Global Medical Affairs, Glenmark Pharmaceuticals Ltd, Mumbai, India. ${ }^{5}$ Clinical Development, Glenmark Pharmaceuticals Ltd, Mumbai, India. ${ }^{6}$ Clinical Research Operations, Glenmark Pharmaceuticals Ltd, Mumbai, India. ${ }^{7}$ Clinical Operations, Glenmark Pharmaceuticals Ltd, Waterford, UK.

Corresponding author: Sagar Panchal (bqpub2019@gmail.com)

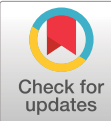

This version is distributed under the terms of the Creative Commons Attribution Non-Commercial Licence 4.0. For commercial reproduction rights and permissions contact permissions@ersnet.org

This article has supplementary material available from openres.ersjournals.com

Received: 12 April 2021 Accepted: 7 May 2021

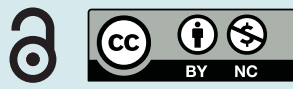

Shareable abstract (@ERSpublications)

Airz-FF (GB/FF/FP) is the first SITT combination launched in India for COPD. Its efficacy is comparable to open-triple therapy (GB+FF/FP); and it is safe and well tolerated in symptomatic COPD patients with history of exacerbations. https://bit.ly/33MHXVv

Cite this article as: Salvi S, Balki A, Krishnamurthy S, et al. Efficacy and safety of single-inhaler triple therapy of glycopyrronium, formoterol and fluticasone in patients with COPD: a double-blind, randomised controlled trial. ERJ Open Res 2021; 7: 00255-2021 [DOI: 10.1183/23120541.00255-2021].

Abstract

Background The aim of this work was to investigate the safety and efficacy of single-inhaler triple therapy with $12.5 \mu \mathrm{g}$ glycopyrronium (GB)/12 $\mu \mathrm{g}$ formoterol fumarate (FF)/250 $\mu$ g fluticasone propionate (FP), compared to $50 \mu \mathrm{g}$ GB co-administered with a fixed dose of $12 \mu \mathrm{g}$ FF/250 $\mu \mathrm{g}$ FP in subjects with COPD.

Methods This was a phase 3, randomised, double-blind, active-control, parallel-group, noninferiority study conducted at 20 sites across India. COPD patients aged $\geqslant 40$ to $\leqslant 75$ years, with forced expiratory volume in $1 \mathrm{~s}\left(\mathrm{FEV}_{1}\right)$ /forced vital capacity (FVC) $<0.70$, using mono/dual therapy with inhaled corticosteroids (ICSs), long-acting muscarinic antagonists (LAMAs), or long-acting $\beta$-agonists (LABAs) for $\geqslant 1$ month, were included. Subjects were randomised 1:1 to GB/FF/FP or GB+FF/FP for 12 weeks. The primary efficacy end-point was the change from baseline in trough $\mathrm{FEV}_{1}$ at the end of 12 weeks. The study is registered with the Clinical Trials Registry of India (identifier number: CTRI/2019/01/017156).

Results Between 23 March 2019 and 14 February 2020, 396 subjects were enrolled, with 198 patients each in the fixed-triple (GB/FF/FP) and open-triple (GB+FF/FP) groups. The difference in least-square mean (LSM) changes in pre-dose $\mathrm{FEV}_{1}$ from baseline at 12 weeks was noninferior between the groups $(p<0.05)$. The LSM change from baseline in post-dose $\mathrm{FEV}_{1}$ was comparable $(\mathrm{p}=0.38)$. A superiority test showed comparable efficacy $(p=0.12)$ for the difference in mean change from baseline in trough $\mathrm{FEV}_{1}$ between the groups. Adverse events (mild or moderate) were recorded in $25.3 \%$ and $24.9 \%$ of subjects in the GB/FF/FP and GB+FF/FP groups.

Conclusions Fixed triple therapy with GB/FF/FP provides comparable bronchodilation and lung function improvement as open-triple therapy. It is safe and well tolerated in symptomatic COPD patients with a history of exacerbations.

\section{Introduction}

COPD, characterised by airflow limitation and persistent respiratory symptoms, is a common disease, which is both preventable and treatable [1]. It is the third leading cause of death worldwide, after ischaemic heart disease and stroke [2]. Triple therapy (inhaled corticosteroids (ICSs)/long-acting $\beta$-agonists (LABAs)/long-acting muscarinic antagonists (LAMAs)) is recommended in the Global Initiative for Chronic Obstructive Lung Disease (GOLD) management strategy for COPD in patients with clinically significant symptoms despite treatment with ICSs/LABAs or LABAs/LAMAs, and who are at an increased 
risk for frequent or severe exacerbations [1]. Compared to dual therapy (LABAs/LAMAs or ICSs/LABAs), triple therapy has shown a significant reduction in moderate or severe COPD exacerbations, improvement in lung function, and quality of life of patients [3].

A single-inhaler triple therapy (SITT) containing ICSs/LABAs/LAMAs reduces treatment complexity leading to better adherence rates and improved clinical outcomes and can reduce healthcare costs associated with COPD $[4,5]$. The circadian variability of symptoms is a relatively neglected area in the management of COPD. The twice-daily dosing of bronchodilators is considered to be a useful approach by experts for controlling troublesome nocturnal symptoms and those symptoms present while being awake, in many symptomatic COPD patients [6]. However, twice-daily SITT dry powder inhaler (DPI) is currently not available for the management of COPD in major parts of the world, including India.

To the best of our knowledge, Airz-FF (12.5 $\mu \mathrm{g}$ glycopyrronium/12 $\mu \mathrm{g}$ formoterol fumarate (FF)/250 $\mu \mathrm{g}$ fluticasone propionate (FP) DPI) is the first twice-daily triple DPI and first triple DPI with glycopyrronium for COPD to be launched in India. Glycopyrronium is a LAMA, approved as once-daily and twice-daily formulations with rapid onset of action, sustained bronchodilation, and established safety even at high doses. Glycopyrronium at $12.5 \mu \mathrm{g}$ twice daily has been shown to have comparable bronchodilation as $50 \mu \mathrm{g}$ once daily [7].

Formoterol is a long and rapid-acting LABA that provides better compliance due to rapid onset of action [8]. FP is a potent ICS. The daily approved dose of $1000 \mu \mathrm{g}$ in COPD is known to be associated with the risk of pneumonia; however, lower doses such as $500 \mu \mathrm{g}$ daily, have been found to be associated with comparable incidences of pneumonia, similar to other ICSs in COPD [9-11].

A single DPI, combining formulations of FP, FF, and glycopyrronium bromide (GB) has been developed for the first time to simplify the treatment regimen of COPD in India. In our study, we aimed to evaluate the efficacy and safety of fixed-dose combination (FDC) DPI of $12.5 \mu \mathrm{g} \mathrm{GB} / 12 \mu \mathrm{g} F F / 250 \mu \mathrm{g}$ FP, twice daily, in comparison to open-triple therapy of $50 \mu \mathrm{g}$ GB once daily co-administered with fixed-dose DPI of $12 \mu \mathrm{g} \mathrm{FF} / 250 \mu \mathrm{g}$ FP twice daily in subjects with COPD.

\section{Methods}

Study design

Our study was a phase 3, randomised, double-blind, double-dummy, active-control, parallel-group, noninferiority study, conducted at 20 sites across India. Subjects who met the inclusion and exclusion criteria at the screening visit entered a 2-week open-label run-in period, during which they received an open-label FDC of DPI $12 \mu \mathrm{g} \mathrm{FF} / 250 \mu \mathrm{g}$ FP (FF/FP), one inhalation twice daily and pressurised metered-dose inhaler (pMDI) salbutamol as rescue medication. At the end of a 2-week run-in period, subjects were randomised 1:1 to one of the two treatment groups (figure 1).

This study was conducted in accordance with the Declaration of Helsinki and Good Clinical Practice according to International Conference on Harmonization guidelines and was reviewed and approved by the ethics committee/institutional review board of the respective study centres. A properly executed, written, informed consent was obtained from each subject before entering into the trial.

\section{Patients}

Eligible patients were male or female, aged $\geqslant 40$ to $\leqslant 75$ years, current or ex-smokers (cigarette or bidi (a thin hand-rolled cigarette available in the Indian subcontinent)), with a smoking history of at least 10 pack-years; and had a diagnosis of COPD (as defined by the GOLD guidelines, 2017 [12]). The post-bronchodilator ratio of forced expiratory volume in $1 \mathrm{~s}\left(\mathrm{FEV}_{1}\right)$ and forced vital capacity (FVC) was $<0.70$, with post-bronchodilator $\mathrm{FEV}_{1} \geqslant 30 \%$ and $<80 \%$ of predicted, history of at least two exacerbations of COPD within 12 months before screening, and with modified Medical Research Council (mMRC) dyspnoea grade $\geqslant 2$. The subjects used ICSs with or without LABAs (as a free or fixed combination), or ICSs with LAMAs, or LABAs with LAMAs (as a free or fixed combination), or LAMA monotherapy as maintenance treatment for at least 1 month before screening. All patients provided written informed consent before any study-related procedure.

We excluded patients from the study if they had asthma, hospitalisation for COPD exacerbation or pneumonia within 3 months before screening, used oral/depot corticosteroids or antibiotics for COPD exacerbation within 6 weeks before the screening, had clinically significant laboratory abnormality or a clinically significant condition (as judged by the investigator). Full inclusion and exclusion criteria, and blinding and allocation concealment are provided in the supplementary appendix. 


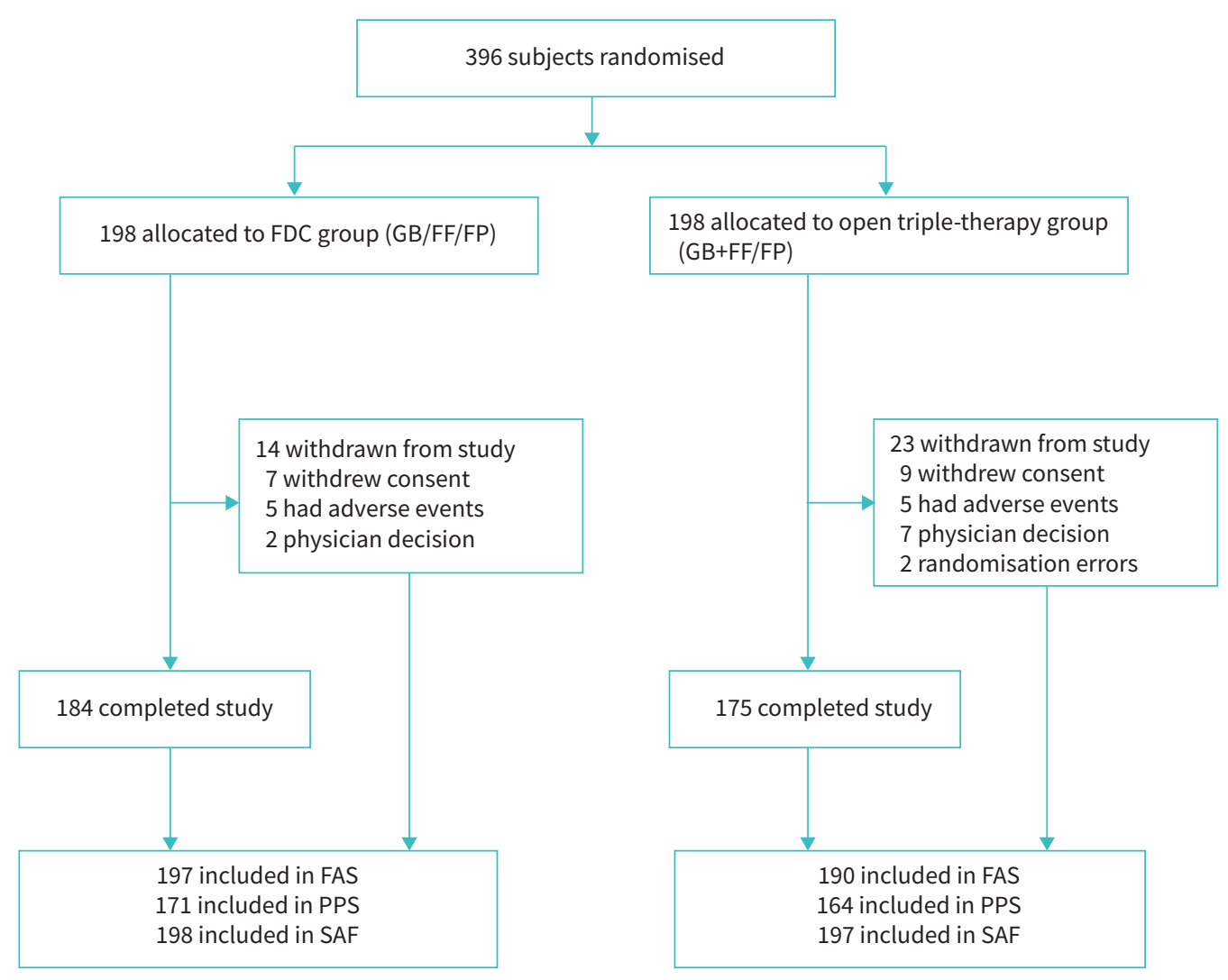

FIGURE 1 Study CONSORT diagram. GB: glycopyrronium; FF: formoterol fumarate; FP: fluticasone propionate; FDC: fixed-dose combination; FAS: full analysis set; PPS: per-protocol set; SAF: safety analysis population.

\section{Procedures}

After the run-in period, subjects with $>80 \%$ compliance with study treatment (ICS/LABA) were randomised in the ratio of $1: 1$ to GB/FF/FP or GB+FF/FP for 12 weeks of treatment. After randomisation, clinic visits were conducted at weeks 2, 4, 8, and 12 (end-of-treatment (EOT) visit), during the treatment period. The follow-up visit was 2 weeks after the EOT visit. At every clinic visit, a medical examination was performed, adverse events (AEs) were recorded, vital signs were evaluated and change in medication was recorded, the subject diary was reviewed, compliance was checked with study medication, mMRC questionnaire was administered, rescue medication was reviewed, and if required, salbutamol was dispensed. Blood and urine investigations, ultrasonography (USG) abdomen, electrocardiograph (ECG), and intra-ocular pressure (IOP) measurement were performed on day 2 of visit 6 . At the follow-up visit, day 98, medical history, examination, AEs, change in medication were recorded, the subject diary was reviewed, mMRC questionnaire was administered, and spirometry was conducted.

\section{Outcomes}

Efficacy was assessed by measuring $\mathrm{FEV}_{1}$ and FVC using spirometry. Three acceptable manoeuvres were required to be performed for each time point and the highest values measured were recorded. The primary efficacy end-point was the change from baseline in trough $\mathrm{FEV}_{1}$ at the end of 12 weeks of treatment. Baseline $\mathrm{FEV}_{1}$ was defined as the average of values from measurements at $15 \mathrm{~min}$ and $45 \mathrm{~min}$ before the first dose of study medication. Trough $\mathrm{FEV}_{1}$ was defined as the average of values from measurements at $23 \mathrm{~h} 15 \mathrm{~min}$ and $23 \mathrm{~h} 45 \mathrm{~min}$ from the time of the previous day’s morning dose. Secondary efficacy end-points included change from baseline in $1 \mathrm{~h}$ post-dose $\mathrm{FEV}_{1}$ at week 12 of treatment, change from baseline in trough FVC at week 12 of treatment, rescue medication use averaged over week 11 and 12 of treatment, frequency of exacerbations (an acute worsening of respiratory symptoms that resulted in additional therapy) and frequency of hospitalisation during 0 to 12 weeks of treatment in both the arms and change from baseline in mMRC score. Safety assessments consisted of monitoring and recording all AEs (including severity as mild, moderate, and severe, as per the assessment of the severity of AEs) and serious AEs (SAEs); regular monitoring of vital signs, ECG, USG examination for urinary retention, ophthalmic assessment for IOP; and physical examinations. 


\section{Statistical analysis}

At an estimated treatment difference of $0 \mathrm{~mL}$ in change from baseline in trough $\mathrm{FEV}_{1}$ between the two treatments, with a noninferiority margin of $80 \mathrm{~mL}$ and an estimated standard deviation (SD) of $250 \mathrm{~mL}$ [13] at 0.05 significance level, a sample size of 336 subjects (168 subjects per group) was estimated to provide a power of $90 \%$. Considering a $15 \%$ drop out, 396 subjects were enrolled in the study.

The primary efficacy analyses were performed on the modified intent-to-treat (mITT) population (all randomised subjects who received at least one dose of the investigational product, who had a nonmissing baseline measurement, and at least one post-baseline efficacy measurement for the primary efficacy variable) and per-protocol set (PPS) population (all randomised subjects who received at least one dose of study medication, completed the study, and did not have any major protocol deviations) using mixed-effect model repeated measure (MMRM). Sensitivity analysis was done by analysis of covariance (ANCOVA) with the last observation carried forward (LOCF). The secondary efficacy analysis was performed using the full analysis set (FAS).

Safety analyses used the safety population (all randomised patients who received at least one dose of study treatment). AEs were coded using the Medical Dictionary for Regulatory Activities (MedDRA) (version 20.0). All continuous laboratory parameters were summarised using descriptive statistics in the safety population. There was no change in the planned analysis or conduct of the study.

Statistical analyses were performed with SAS 9.4 version or the latest available version (SAS Institute Inc., Cary, NC, USA). The study is registered with the Clinical Trials Registry of India (identifier number: CTRI/2019/01/017156).

\section{Results}

The study was conducted between 23 March 2019 and 14 February 2020; 396 subjects were enrolled and randomised to FDC of $12.5 \mu \mathrm{g} \mathrm{GB} / 12 \mu \mathrm{g}$ FF/250 $\mu \mathrm{g}$ FP (fixed-triple group) (n=198) or $50 \mu \mathrm{g}$ GB with FDC of $12 \mu \mathrm{g} \mathrm{FF} / 250 \mu \mathrm{g}$ FP (open-triple group) (n=198). Of the 396 subjects, 359 (90.7\%) completed the study. A total of 37 subjects (9.3\%) were withdrawn from the study. The most common reason for discontinuation was withdrawal by subject $(16(4 \%))$, followed by discontinuation due to adverse event (10 (2.5\%)), physician decision (9 (2.3\%)), and randomised by mistake with study treatment (2 (0.5\%)). Of the 396 randomised subjects, 395 (99.7\%) were included in the safety population, 387 (97.7\%) were included in the mITT/FAS population, and 335 (84.6\%) were included in the PPS population (figure 1).

Baseline demographic and clinical characteristics were generally similar between study treatment and control groups (table 1). All enrolled subjects were Asian, and the number of male subjects was higher (95.1\%). The mean age was 61.1 years (median: 62.0 years; range: 40 years to 74 years); $56.8 \%$ of subjects in the open-triple (GB+FF/FP) group had severe COPD compared to $52.3 \%$ in the fixed-triple (GB/FF/FP) group. The mean percentage $\mathrm{FEV}_{1}$ reversibility in the $\mathrm{GB} / \mathrm{FF} / \mathrm{FP}$ group was $10.9 \%$, in comparison to $12.1 \%$ in the $\mathrm{GB}+\mathrm{FF} / \mathrm{FP}$ group.

The adjusted least-square mean (LSM) changes from baseline in pre-dose $\mathrm{FEV}_{1}$ at week 12 in the mITT population (primary efficacy variable) was $0.062 \mathrm{~L}$ (SE: 0.02) for fixed triple (GB/FF/FP), and $0.098 \mathrm{~L}$ (0.02) for open-triple (GB+FF/FP). The LSM difference (90\% CI) between groups was noninferior (NI) $(-0.038$ L $(90 \%$ CI $-0.078-0.003), \mathrm{p}<0.05)$ (table S1). A superiority test demonstrated comparable efficacy $\left(\mathrm{p}=0.12\right.$ ) for the difference in mean change from baseline in trough $\mathrm{FEV}_{1}$ between the groups.

The LSM change from baseline in post-dose $\mathrm{FEV}_{1}$ in the mITT population (the key secondary efficacy variable) at week 12 was statistically significant within the group (GB/FF/FP: $-0.1450 \pm 0.24 \mathrm{~L}, \mathrm{p}<0.001$ and $\mathrm{GB}+\mathrm{FF} / \mathrm{FP}:-0.1726 \pm 0.24 \mathrm{~L}, \mathrm{p}<0.001$ ) and comparable between the fixed-triple and open-triple group (LSM $-0.022 \mathrm{~L}$ (95\% CI $-0.073-0.028) ; \mathrm{p}=0.38$ ). There was a statistically significant reduction in the use of rescue medication in the fixed triple $(\mathrm{GB} / \mathrm{FF} / \mathrm{FP})$ group $(\mathrm{p}<0.01)$ from baseline; and the results were comparable $(p=0.34)$ between the groups with an LSM change from baseline for rescue medication use averaged over week 11 and 12 of treatment as -0.122 puffs per day in the fixed-triple group compared to -0.152 puffs per day in the open-triple group. The trough FVC changes from baseline at week 12 were comparable between the groups $(-0.022 \pm 0.03) \mathrm{L}(95 \% \mathrm{CI}-0.083-0.039) ; \mathrm{p}=0.48)$ (figures 2 and 3). Statistically significant improvement in the mMRC score was observed in the fixed-triple group at week 2, which was sustained till week $12(\mathrm{p}<0.01)$, whereas the LSM change in mMRC score at week 12 between the groups ( -0 (95\% CI $-0.1-0.1)$; $\mathrm{p}=0.96$ ) was comparable (table S2). 


\section{TABLE 1 Summary of demographic and other baseline characteristics}

\begin{tabular}{|c|c|c|}
\hline & $\begin{array}{l}\text { GB50 once daily+FDC FF12/FP250 twice } \\
\text { daily }\end{array}$ & $\begin{array}{l}\text { FDC GB12.5/FF12/FP250 twice } \\
\text { daily }\end{array}$ \\
\hline Subjects $\mathrm{n}$ & 190 & 197 \\
\hline Age (years) & $60 \pm 8.4$ & $62.1 \pm 7.7$ \\
\hline \multicolumn{3}{|l|}{ Sex } \\
\hline Female & $9(4.7)$ & $10(5.1)$ \\
\hline Male & $181(95.3)$ & $187(94.9)$ \\
\hline \multicolumn{3}{|l|}{ Race } \\
\hline Asian & $190(100)$ & $197(100)$ \\
\hline Weight (kg) & $57.75 \pm 11.5$ & $56.52 \pm 12$ \\
\hline Height $(\mathrm{cm})$ & $163.41 \pm 6.8$ & $162.25 \pm 7.3$ \\
\hline \multicolumn{3}{|l|}{ Severity } \\
\hline Mild COPD: $\mathrm{FEV}_{1}$ post-bronchodilator $\geqslant 80 \%$ predicted & $1(0.5)$ & 0 \\
\hline $\begin{array}{l}\text { Moderate COPD: } \mathrm{FEV}_{1} \text { post-bronchodilator }<80 \% \text { and } \geqslant 50 \% \\
\text { predicted }\end{array}$ & $81(42.6)$ & $94(47.7)$ \\
\hline $\begin{array}{l}\text { Severe COPD: } \mathrm{FEV}_{1} \text { post-bronchodilator }<50 \% \text { and } \geqslant 30 \% \\
\text { predicted }\end{array}$ & $108(56.8)$ & $103(52.3)$ \\
\hline $\mathrm{FEV}_{1}$ reversibility $(\mathrm{mL})$ & $102.2 \pm 141.7$ & $103.1 \pm 131$ \\
\hline $\mathrm{FEV}_{1}$ reversibility (\%) & $12.1 \pm 20.6$ & $10.9 \pm 14.3$ \\
\hline$\%$ predicted $\mathrm{FEV}_{1}$ & $48.2 \pm 12.3$ & $48.6 \pm 11.8$ \\
\hline Smoking (pack-years) & $20.454 \pm 11.4$ & $21.087 \pm 12.7$ \\
\hline
\end{tabular}

Compliance to treatment was high, with a median of 98.06\% (SD: 3.99) and 97.76\% (SD:5.06) of doses taken in the fixed-triple group, and open-triple group, respectively. Median exposure was 85 days (21-110 days) for the fixed-triple group and 84 days (1-107 days) for the open-triple group.

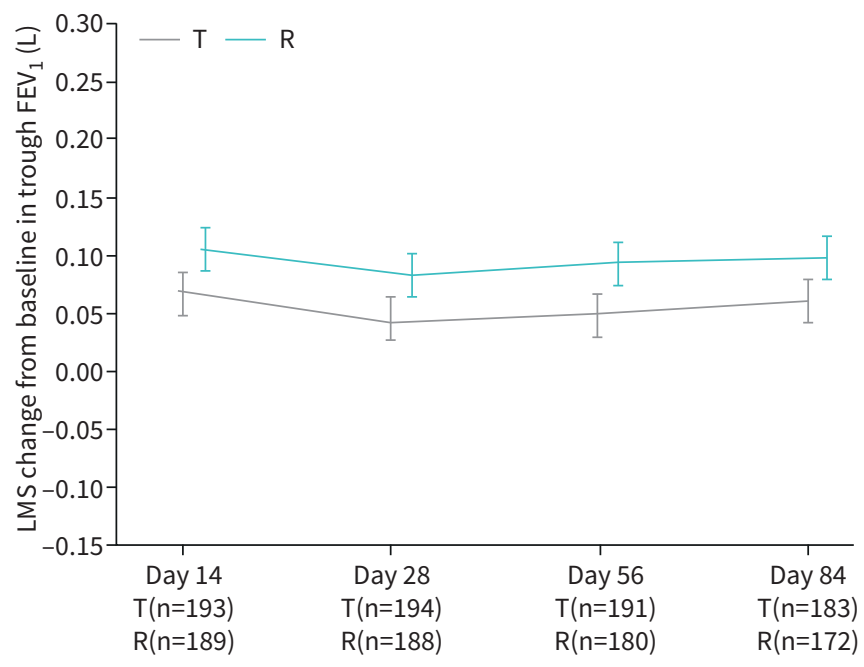

FIGURE 2 Plot of least-square means (LSM) \pm SE of change from baseline of trough forced expiratory volume in $1 \mathrm{~s}\left(\mathrm{FEV}_{1}\right)$ with mixed-effect model repeated measure (MMRM) full analysis set. R: $50 \mu \mathrm{g}$ glycopyrronium (GB) once dailly + fixed-dose combination (FDC) $12 \mu \mathrm{g}$ formoterol fumarate (FF) $/ 250 \mu \mathrm{g}$ fluticasone propionate (FP) twice daily; T: FDC $12.5 \mu \mathrm{g} \mathrm{GB} / 12 \mu \mathrm{g} \mathrm{FF} / 250 \mu \mathrm{g}$ FP twice daily. p-values of $\mathrm{NI}$ for T versus R at weeks 2, 4, 8, and 12 were $<0.05,<0.05,0.08$ and $<0.05$, respectively. $\mathrm{p}$-values of SP for T versus $\mathrm{R}$ at weeks $2,4,8$, and 12 were $0.10,0.09,0.07$ and 0.13 , respectively. $\mathrm{p}$-values of change from baseline for $\mathrm{T}$ at weeks $2,4,8$, and 12 were $<0.001,0.003,0.008$ and $<0.001$, respectively. $\mathrm{p}$-values of change from baseline for $\mathrm{R}$ at weeks $2,4,8$, and 12 were $<0.001,<0.001,<0.001$ and $<0.001$, respectively. LSM of change from baseline of trough $\mathrm{FEV}_{1}(\mathrm{~L})$ was calculated with MMRM method with treatment, centre, visit, and treatment-by-visit interaction as fixed-effect factors and lung function $\mathrm{FEV}_{1}(\mathrm{~L})$ at baseline as covariate. NI: noninferiority; SP: superiority. 

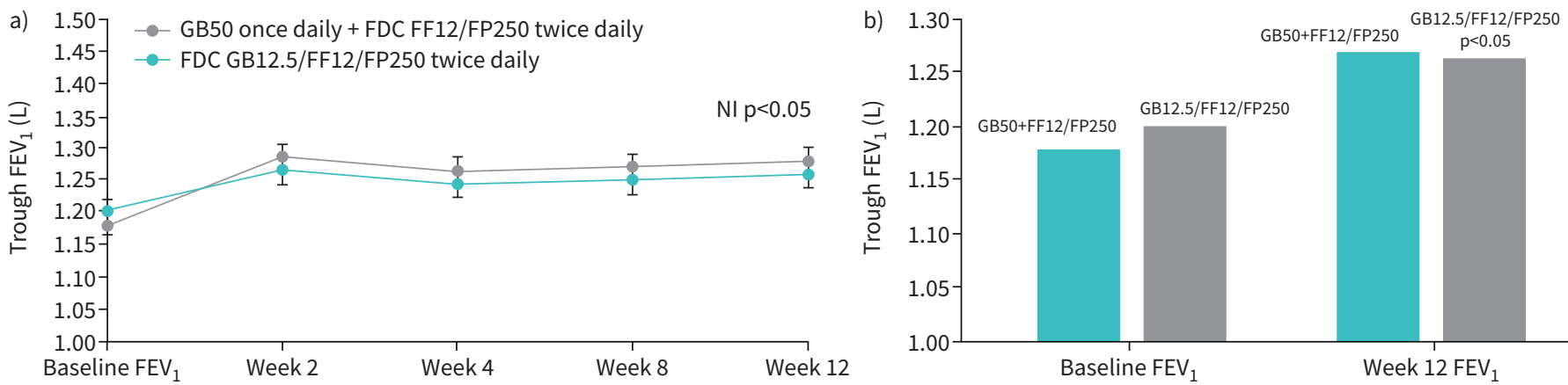

FIGURE 3 Lung function trough forced expiratory volume in $1 \mathrm{~s} \mathrm{(FEV})_{1}$ by visits in full analysis set population: a) at baseline, weeks 2, 4, 8, and 12; b) at baseline and week 12. GB: glycopyrronium; FF: formoterol fumarate; FP: fluticasone propionate; FDC: fixed-dose combination; $\mathrm{NI}$ : noninferiority.

In the FAS, 8 out of 197 (4.1\%) of the subjects in the fixed-triple group reported at least one exacerbation of COPD during the 12-week treatment period compared to 10 out of 190 (5.3\%) in the open-triple group. Similarly, the rate of hospitalisation between the groups was comparable at the end of 12 weeks $(1.5 \%$ (fixed triple) versus $0.5 \%$ (open triple), $\mathrm{p}=0.62$ ) (table S3).

A similar proportion of patients had AEs in both groups, $25.3 \%$ in the GB/FF/FP group and $24.9 \%$ in the $\mathrm{GB}+\mathrm{FF} / \mathrm{FP}$ group. The majority of events were mild or moderate in severity. The majority of the treatment-emergent adverse events (TEAEs) were mild to moderate and were resolved. Four subjects reported 10 SAEs in the study. In the GB+FF/FP group, one $(0.5 \%)$ subject reported seven SAEs (considered not related to study medication). In the GB/FF/FP group, three (1.5\%) subjects reported three SAEs (all three subjects reported acute exacerbation of COPD). All three events were resolved without sequelae. The TEAEs that led to permanent discontinuation of the study drug were reported in 5 out of 198 (2.5\%) in the GB/FF/FP group and 5 out of 197 (2.5\%) in the GB+FF/FP group. All the TEAEs leading to permanent discontinuation were COPD exacerbations. The TEAEs that were observed in $\geqslant 2 \%$ of subjects with the use of GB/FF/FP were COPD, cough, urinary retention, pyrexia, nasopharyngitis, and upper respiratory tract infection (table 2).

\section{Discussion}

The study met its primary efficacy end-point in terms of noninferior bronchodilation (pre-dose $\mathrm{FEV}_{1}$ ) with treatment in the fixed-triple (GB/FF/FP) group as compared to the open-triple group, which was sustained over 12 weeks. The change from baseline in $\mathrm{FEV}_{1}$ in the GB/FF/FP group was consistent with previous studies evaluating fixed-triple therapy [14]. In the TRINITY study, extra-fine fixed-triple therapy (BDP/FF/ GB) treatment had clinical benefits in patients with similar COPD profiles. At week 52, the adjusted mean changes in pre-dose $\mathrm{FEV}_{1}$ from baseline were $0.082 \mathrm{~L}$ (95\% CI 0.065-0.100) for fixed-triple and $0.085 \mathrm{~L}$ (0.061-0.110) for open-triple therapy. This is comparable to our study in which adjusted LSM changes from baseline in pre-dose $\mathrm{FEV}_{1}$ at week 12 in the mITT population were $0.062 \mathrm{~L}$ (SE 0.02) for fixed-triple (GB/FF/FP), and $0.098 \mathrm{~L}(0.02)$ for open-triple (GB+FF/FP) therapy. Though in our study, the fixed-triple group received half the total daily dose of glycopyrronium $(12.5 \mu \mathrm{g}$ twice daily) as compared to the open-triple arm (50 $\mu \mathrm{g}$ once daily), the bronchodilation and other clinical outcomes achieved were comparable in both the arms, further supporting the findings of a previous study, which showed that $12.5 \mu \mathrm{g}$ glycopyrronium twice daily has comparable efficacy as compared to $50 \mu \mathrm{g}$ glycopyrronium once daily in the improvement of trough $\mathrm{FEV}_{1}$ in COPD [7].

Secondary end-points supported the results of the primary end-point. No significant differences were observed between GB/FF/FP and GB+FF/FP ( $p>0.05$ ) for change from baseline in post-dose $F_{1} V_{1}$ and trough FVC at week 12, rescue medication use averaged over week 11 and 12, change from baseline in mMRC score, the proportion of subjects with exacerbations, and proportion of subjects with hospitalisations.

There was no difference between the two treatment groups for rescue medication use $(p=0.34)$, which is comparable to results from the TRINITY study [14]. The mMRC score improved significantly from week 2 onwards in the fixed-triple group ( $<<0.01$ at all the visits) and was comparable in the open-triple group ( $p=0.96$ ), at all study visits. 


\section{TABLE 2 Summary of subjects with treatment-emergent adverse events (TEAEs) (safety population)}

\begin{tabular}{|c|c|c|c|}
\hline & GB50 once daily+FDC FF12/FP250 twice daily & FDC GB12.5/FF12/FP250 twice daily & Total \\
\hline Subjects $\mathrm{n}$ & 197 & 198 & 395 \\
\hline TEAE & $49(24.9)$ & $50(25.3)$ & $99(25.1)$ \\
\hline AE leading to death & $1(0.5)$ & 0 & $1(0.3)$ \\
\hline AE leading to permanent discontinuation of IP & $5(2.5)$ & $5(2.5)$ & $10(2.5)$ \\
\hline AE leading to early termination & $5(2.5)$ & $5(2.5)$ & $10(2.5)$ \\
\hline No & $37(18.8)$ & $30(15.2)$ & $67(17.0)$ \\
\hline \multicolumn{4}{|l|}{ SAE by relationship } \\
\hline Yes & 0 & $1(0.5)$ & $1(0.3)$ \\
\hline No & $1(0.5)$ & $2(1.0)$ & $3(0.8)$ \\
\hline \multicolumn{4}{|l|}{ AE by severity } \\
\hline Mild & $38(19.3)$ & $37(18.7)$ & $75(19.0)$ \\
\hline
\end{tabular}

Data are presented as $\mathrm{n}(\%)$, unless otherwise stated. Percentages are based on the number of subjects in the safety population in the respective treatment groups. Study drug-related AE is defined as an AE with a relationship considered and reported as "Related" by the investigator. Subjects with more than one AE were counted only once. AE: adverse event; FDC: fixed-dose combination; FF12: $12 \mu \mathrm{g}$ formoterol fumarate; FP250: $250 \mu \mathrm{g}$ fluticasone propionate; GB12.5: $12.5 \mu \mathrm{g}$ glycopyrronium; GB50: $50 \mu \mathrm{g}$ glycopyrronium; IP: investigational product; SAE: serious adverse event.

We did not evaluate the risk of exacerbation over a 52 week-period; however, the frequency of exacerbation was comparable between both the fixed-triple and open-triple groups $(4.1 \%$ and $5.3 \%)$ over the 12 week-period. In the TRINITY study, the rates of moderate-to-severe COPD exacerbations were 0.46 per patient per year for fixed-triple and 0.45 for open-triple groups [14]. Clinical benefits of SITT in terms of reduction in the rate of exacerbations have been demonstrated in global clinical trials, such as ETHOS, KRONOS, TRIBUTE, FULFILL, IMPACT, and are highly plausible with GB/FF/FP SITT [15-19].

Medication adherence is a key factor in achieving desired clinical outcomes. However, several epidemiological studies suggest that adherence remains suboptimal in the majority of patients, especially in COPD [20, 21]. The complexity of regimens is one of the very important factors for poor adherence to therapy; reducing treatment complexity could lead to better adherence rates and improved clinical outcomes for patients with COPD, and can reduce the associated healthcare costs $[4,5]$. In our study, overall drug compliance was $98.06 \%$ in the GB/FF/FP group, which was comparable to landmark SITT trials, such as TRILOGY, TRIBUTE, and TRINITY trials (adherence rate 95-98\%) [14, 17, 22]. Higher adherence could have contributed to the better clinical outcomes observed in this study.

This fixed triple therapy/SITT approach did not result in any unexpected safety findings, with no clinically relevant differences between the two groups. No increased incidence of pneumonia was noted with both the triple therapies, as shown in a meta-analysis of 14 randomised controlled trials evaluating SITT versus dual therapy (LABA/LAMA) in COPD [11].

Overall, the incidences of AEs and TEAEs were low, and comparable across the two treatment groups. The majority of the TEAEs were mild or moderate in intensity and not related to the study drug. The incidence of clinically significant abnormalities in laboratory parameters, physical examination parameters, and USG findings was low. No clinically significant abnormalities in vital sign parameters or ECG were reported in the study. In summary, the FDC of $12.5 \mu \mathrm{g} \mathrm{GB} / 12 \mu \mathrm{g}$ FF/250 $\mu \mathrm{g}$ FP as a DPI in adult subjects with COPD was found to be safe and well tolerated.

The strength of the study was a robust double-blind, randomised, controlled study design, which helped in minimising the effect of bias and confounding on the study results. In this study, all the subjects received FF+FP during the 2-week run-in period and were then randomised to one of the two treatment groups. Thus, the study practically compared the efficacy and safety of $12.5 \mu \mathrm{g}$ GB twice daily (in the FDC test group) versus $50 \mu \mathrm{g}$ GB once daily (in the reference group), in subjects receiving background treatment of ICSs+LABAs. The comparators were selected to mimic the current clinical practice of co-administration of LAMAs with FDC ICSs/LABAs in different inhaler devices. In this study, statistical analysis was 
conducted in both FAS and PPS populations, using MMRM and ANCOVA with LOCF with and without outlier treatments in accordance with the guidance from the US Food and Drug Administration.

The results of the study should also be viewed in light of a few limitations. The study had a noninferiority design and was not designed to demonstrate the contribution of each of the mono components over the others in the treatment of COPD. There was no placebo arm in the study to demonstrate assay sensitivity of the study design and conduct. The placebo arm was not included owing to the ethical concern of denying triple treatment in patients with group ' $\mathrm{D}$ ' COPD. The study was of short duration and not designed to assess the effect of GF/FF/FB on exacerbations. So, the exacerbation data in the study may be considered only as informative.

\section{Conclusion}

The FDC of $12.5 \mu \mathrm{g} \mathrm{GB} / 12 \mu \mathrm{g}$ FF/250 $\mu \mathrm{g}$ FP was associated with significant improvements from baseline in trough $\mathrm{FEV}_{1}$, post-dose $\mathrm{FEV}_{1}$, trough $\mathrm{FVC}$, mMRC score, and rescue medication use. Overall, this study demonstrated that SITT of GB/FF/FP provides comparable bronchodilation and lung function improvement, similar to open-triple therapy. The FDC of GB/FF/FP as a DPI was found to be safe and well tolerated for use in subjects with COPD.

Acknowledgement: We would like to thank all the clinical investigators (Boyilla Nagaraju, Amit Dhamija, Abhinandan Bhikchand Mutha, Shivani Swami, Rajkumar Nikalje, Ashish Omprakash Goyal, Swapnil Suresh Sakhala, Balkrishna Onkar Tayade, Vinit Niranjane, Shashi Prakash Maurya, Sandeep Kumar Gupta, Keyur Brahme, Amit Patel, Anand Patel, Vijay Popatlal Surana, Manish Kumar Jain and Ashish Kumar) and the Glenmark internal team (Sunil Jagdale, Vishakha Utekar, Reshma More, Manali Mokal, Megha Gupta, Yashodhan Warke, Sharon Lobo, Sagar Borle, Prafulla Shetty, Wen Wu, Yogesh Gadage and Krishna Gupta) for their contribution in execution of the study. Also, we would like to thank BioQuest solutions for providing editorial assistance.

This study is registered at www.ctri.nic.in with identifier number CTRI/2019/01/017156. At an organisational level, we do not have any plan to share data other than this publication. This was regulatory trial, so data has been shared/presented with the Indian regulatory agency (DCGI). However, derived data supporting the findings of this study are available from the corresponding author (Sagar Panchal; sagar.panchal@glenmarkpharma.com) on request.

Conflict of interest: S. Salvi has nothing to disclose. A. Balki has nothing to disclose. S. Krishnamurthy has nothing to disclose. S. Panchal is an employee of Glenmark Pharmaceuticals. S. Patil is an employee of Glenmark Pharmaceuticals. R. Kodgule is an employee of Glenmark Pharmaceuticals. H. Khandagale is an employee of Glenmark Pharmaceuticals. A. Pendse is an employee of Glenmark Pharmaceuticals. W. Wu is an employee of Glenmark Pharmaceuticals. S. Rangwala is an employee of Glenmark Pharmaceuticals. M. Tandon is an employee of Glenmark Pharmaceuticals. H. Barkate is an employee of Glenmark Pharmaceuticals.

Support statement: This study was supported by Glenmark Pharmaceuticals Ltd. The funder was responsible for the design and analysis of the study, oversaw its conduct, and was responsible for preparing the study report. All authors had full access to all of the data, with the lead author being responsible for the decision to submit for publication. Funding information for this article has been deposited with the Crossref Funder Registry.

\section{References}

1 Global Initiative for Chronic Obstructive Lung Disease. 2021 Report: global strategy for prevention, diagnosis and management of COPD. https://goldcopd.org/wp-content/uploads/2020/11/GOLD-REPORT-2021-v1.1-25Nov20_ WMV.pdf Date last accessed: March 30, 2021.

2 World Health Organization. Global Health Observatory (GHO) data. Mortality and global health estimates. www.who.int/gho/mortality_burden_disease/en/ Date last accessed: June, 2020. Date last updated: 2019.

3 Yayuan Z, Jianhong Z, Yuyu L, et al. Triple therapy in the management of chronic obstructive pulmonary disease: systematic review and meta-analysis. BMJ 2018; 363: k4388.

4 Mäkelä MJ, Backer V, Hedegaard M, et al. Adherence to inhaled therapies, health outcomes and costs in patients with asthma and COPD. Respir Med 2013; 107: 1481-1490.

5 King D, Zhang S, Rosen V, et al. Single versus multiple inhalers in patients with chronic obstructive pulmonary disease (COPD): a systematic literature review. Value Health 2017; 20: A574.

6 Braghiroli A, Braido F, Piraino A, et al. Day and night control of COPD and role of pharmacotherapy: a review. Int J Chron Obstruct Pulmon Dis 2020; 15: 1269-1285.

7 Arievich $\mathrm{H}$, Overend $\mathrm{T}$, Renard $\mathrm{D}$, et al. A novel model-based approach for dose determination of glycopyrronium bromide in COPD. BMC Pulm Med 2012; 12: 74. 
Benhamou D, Cuvelier A, Muir JF, et al. Rapid onset of bronchodilation in COPD: a placebo-controlled study comparing formoterol (Foradil Aerolizer) with salbutamol (Ventodisk). Respir Med 2001; 95: 817-821.

9 Yang $\mathrm{M}, \mathrm{Du} \mathrm{Y}$, Chen $\mathrm{H}$, et al. Inhaled corticosteroids and risk of pneumonia in patients with chronic obstructive pulmonary disease: a meta-analysis of randomized controlled trials. Int Immunopharmacol 2019; 77: 105950.

10 Global Initiative for Chronic Obstructive Lung Disease. 2017 Report: global strategy for prevention, diagnosis and management of COPD. https://goldcopd.org/wp-content/uploads/2016/12/wms-GOLD-2017-Pocket-Guide1.pdf Date last accessed: March 30, 2021.

11 Izquierdo JL, Cosio BG. The dose of inhaled corticosteroids in patients with COPD: when less is better. Int J Chron Obstruct Pulmon Dis 2018; 13: 3539-3547.

12 Cazzola M, Rogliani P, Calzetta L, et al. Triple therapy versus single and dual long-acting bronchodilator therapy in COPD: a systematic review and meta-analysis. Eur Respir J 2018; 52: 1801586.

13 Singh D, Jones PW, Bateman ED, et al. Efficacy and safety of aclidinium bromide/formoterol fumarate fixed-dose combinations compared with individual components and placebo in patients with COPD (ACLIFORM-COPD): a multicentre, randomised study. BMC Pulm Med 2014; 14: 178.

14 Vestbo J, Papi A, Corradi M, et al. Single inhaler extrafine triple therapy versus long-acting muscarinic antagonist therapy for chronic obstructive pulmonary disease (TRINITY): a double-blind, parallel group, randomised controlled trial. Lancet 2017; 389: 1919-1929.

15 Rabe KF, Martinez FJ, Ferguson GT, et al. Triple inhaled therapy at two glucocorticoid doses in moderate-to-very-severe COPD. N Engl J Med 2020; 383: 35-48.

16 Ferguson GT, Rabe KF, Martinez FJ, et al. Triple therapy with budesonide/glycopyrrolate/formoterol fumarate with co-suspension delivery technology versus dual therapies in chronic obstructive pulmonary disease (KRONOS): a double-blind, parallel-group, multicentre, phase 3 randomised controlled trial. Lancet Respir Med 2018; 6: 747-758.

17 Papi A, Vestbo J, Fabbri L, et al. Extrafine inhaled triple therapy versus dual bronchodilator therapy in chronic obstructive pulmonary disease (TRIBUTE): a double-blind, parallel group, randomised controlled trial. Lancet 2018; 391: 1076-1084.

18 Lipson DA, Barnacle $\mathrm{H}$, Birk R, et al. FULFIL trial: once-daily triple therapy for patients with chronic obstructive pulmonary disease. Am J Respir Crit Care Med 2017; 196: 438-446.

19 Lipson DA, Barnhart F, Brealey N, et al. Once-daily single-inhaler triple versus dual therapy in patients with COPD. N Engl J Med 2018; 378: 1671-1680.

20 Khan R, Socha-Dietrich K. Investing in medication adherence improves health outcomes and health system efficiency: adherence to medicines for diabetes, hypertension, and hyperlipidaemia. OECD Health Working Papers. No. 105. Paris, OECD Publishing, 2018. https://doi.org/10.1787/8178962c-en Date last accessed: June, 2019.

21 Van Boven JF, Ryan D, Eakin MN. Enhancing respiratory medication adherence: the role of health care professionals and cost-effectiveness considerations. J Allergy Clin Immunol Pract 2016; 4: 835-846.

22 Singh D, Papi A, Corradi M, et al. Single inhaler triple therapy versus inhaled corticosteroid plus long-acting ß2-agonist therapy for chronic obstructive pulmonary disease (TRILOGY): a double-blind, parallel group, randomised controlled trial. Lancet 2016; 388: 963-973. 